\title{
A Influência dos Recursos Naturais Frente à Colonização do Vale do Macuri
}

The influence of natural resources the colonization of the Vale do Mucuri

\author{
Marcio Schuber Ferreira Figueiredo ${ }^{2}$ \\ Cristiane Xavier Figueiredo
}

\section{Resumo}

O presente artigo foi desenvolvido no intuito de demonstrar, de maneira clara e objetiva, a influência dos recursos naturais frente à colonização do Vale do Mucuri, localizado na região Leste do Estado Minas Gerais - Brasil, tendo como base uma análise sistemática e teórica deste processo. A pesquisa foi realizada a partir do estudo acerca da exploração das riquezas minerais aí presentes e os seus desdobramentos, no que tange ao aumento da população, a devastação ambiental e a conseqüente escassez de riquezas, bem como o desenvolvimento das atividades agropastoril, mercantil, fluvial e sua influência. Os resultados obtidos demonstram a importância dos recursos naturais e sua influência no processo de colonização, refletindo numa relação entre o próprio indivíduo com seu ambiente. Com o povoamento das cidades, percebe-se, claramente, reflexos da exploração de recursos minerais, agropecuários, dos mercados e dos recursos hídricos evidenciando uma devastação ambiental. A existência das cidades e o seu contexto fazem parte deste estudo que utiliza do recurso da revisão de literatura como metodologia, contribuindo para o entendimento acerca da relação direta dos indivíduos e o seu meio ambiente, com ênfase nos conceitos de local, região e território aplicados a esta realidade.

Palavras Chave: recursos naturais, colonização; vale do Mucuri.

\section{Abstract}

This article was developed in order to demonstrate clearly and objectively, the influence of natural resources the colonization of the Vale do Mucuri, located in Eastern Minas Gerais State, Brazil based on a systematic and

\footnotetext{
${ }^{2}$ Marcio Schuber Ferreira Figueiredo: Mestrando em GIT - Gestão Integrada do Território, Diretor Acadêmico Pedagógico da Faculdade Presidente Antônio Carlos de Teófilo Otoni/MG, Professor Substituto do Curso de Direito, Especialista em Educação e Gestão Ambiental - FAZU(2002), Especialista em Docência do Ensino Superior - UNIPAC(2006), Bacharel Direito - FENORD(1999).

Cristiane Xavier Figueiredo: Especialista em Docência do Ensino Superior DOCTUM, Bacharel em Direito - FENORD, Bacharel em Ciência Contábeis DOCTUM, Professora substituta do Curso de Direito da Faculdade Presidente Antônio Carlos de Teófilo Otoni/MG.
} 
theoretical analysis of this process. The survey was conducted from the study on the exploitation of mineral wealth there and their unfoldings, in regard to the increase of population, environmental devastation and the consequent shortage of riches, as well as the development of agricultural activities, mercantil, River and its influence. The results obtained show the importance of natural resources and their influence in the process of colonization, reflecting a relationship between the individual himself with your environment. With the settlement of cities, one realizes clearly reflections of exploitation of mineral resources, agricultural farms, markets and water resources demonstrating environmental devastation. The existence of cities and its context are part of this study that uses the resource as literature review methodology, contributing to the understanding of the direct relationship of individuals and their environment, with emphasis on the concepts of local, region and territory applied to this reality.

Key Words: natural resources, Colonization, vale do Macuri.

\section{RESUMEN:}

El actual artículo fue desarrollado en la intención de demostrar, en claro y la manera objetiva, la influencia él los recursos naturales lo afronta a colocar valle él Mucuri, localizado adentro región al este de Minas Gerais - Brasil, teniendo como base análisis sistemático y teórico de este proceso. La investigación fue llevada a través del estudio referente a la exploración de los regalos mineral de la abundancia allí y de sus unfoldings, en a lo que se refiere al aumento de la población, del devastação ambiente y de la escasez consiguiente de la abundancia, así como el desarrollo del agropastoril de las actividades, mercantil, fluvial y de su influencia. La existencia de las ciudades y de su contexto son parte de este estudio que las aplicaciones del recurso de la revisión de la literatura como metodología, el contribuir para el acuerdo respecto a la relación directa de los individuos y de su ambiente, con énfasis adentro conceptos del lugar, región e el territorio se aplicó a esta realidad.

Palabras clave: recursos naturales, colocando; Vale do Mucuri.

\section{O Povoamento da Região}

A partir da descoberta do ouro e dos diamantes na região do Alto Jequitinhonha, que na linguagem indígena quer dizer que, no jequi (armadilha) tin honha (tem peixe), iniciou-se o processo de colonização regional, tendo por conseqüência, o aumento significativo da população. Tratava-se de uma região procurada por aventureiros que viviam em busca de fortuna e escravos. A região onde havia maior concentração populacional era a que ia do Peçanha a Itamarandiba, e daí a Minas Novas, 
Chapada, Berilo e finalmente São Domingos, que era como se chamava a atual cidade de Virgem da Lapa.

Os rios Jequitinhonha e Mucuri, pouco explorados até a segunda metade do século dezoito, assim como o rio Doce, foram tratados como áreas proibidas pela coroa, sob o pretexto de que esta permanecesse com o controle das riquezas evitando, assim, o contrabando e invasões estrangeiras. Impunha-se, como conseqüência, o monopólio da estrada para o Rio de Janeiro, aberta pelas bandeiras e, assim, melhor controlada. Ocuparam esta região os moradores das tribos Botocudos e Puris, objeto de lendárias conjecturas como os da serra das esmeraldas.

O povoamento da região do rio Mucuri, mas especificamente do seu mais importante afluente, o rio Todos os Santos, se deu de forma inversa, ou seja, não ocorrendo do litoral para o interior, pois sua trilha original nasceu na cidade de Araçuaí, vindo de Minas Novas e passando por Americaninha. Fato é que por não ser inteiramente navegável, o rio Mucuri não promovia o acesso via litoral, afastando invasores que pudessem ameaçar o metal cobiçado, assim como o contrabando e o tráfico de escravos.

\begin{abstract}
Cabe ao município de Theóphilo Ottoni a glória de ter sido um dos primeiros pontos do território brasileiro visitado pelos expedicionários portuguezes, à cata de ouro e de esmeraldas, objetos de lendárias conjecturas.

As notícias transmitidas por Felippe de Guilhem a D. João III, em 1550, participando-lhe que os bugres falavam da existência de uma serra resplandecente junto a um grande rio, despertaram a cobiça do rei que, por vezes, recommendou a Thomé de Souza, então governador geral do Brazil, que mandasse alguns homens pelo sertão dentro a descobrir minas e saber se havia aí ouro, etc. (PORTO, 1929, p. 3).
\end{abstract}

Quando a produção dos garimpos e da lavoura começou a dar sinais de enfraquecimento, a redução desta já era visível, pois o ouro e diamantes mais fáceis ou de superfície, dava lugar a catas mais profundas e perigosas, e a lavoura minguava pela baixa fertilidade do solo, fruto da prática da roça de toco e das várias safras nos mesmos capões de mata. "...nas grotas, pelo contrário, quanto mais próximas das águas, mais férteis são as terras, principalmente aquelas que têm bosques, chamados capões..." (RIBEIRO, 1994. p. 29).

Aqueles moradores do Alto rio Jequitinhonha, de Itamarandiba a Virgem da Lapa logo começaram a invadir a mata, aquela que prometia, segundo a lenda, alcançar a serra das esmeraldas, terra nova, farta, fértil, sem dono, onde as lavouras produziam muito com pouco esforço, fazendo brotar desejo e especulações que já eram vistos em diversas áreas de colonização. "As proibições não foram mais fortes do que o fascínio pelas pedras verdes. As investidas ao sertão continuaram do lado espíritosantense". (ESPINDOLA, 2005. p. 30).

Este movimento de deslocamento para estes vales durou mais de um século e se deu inicialmente pela barra do rio Araçuaí e Jequitinhonha abaixo, povoando e explorando regiões muito férteis como as de Itaobim, Jequitinhonha, Almenara e Salto da Divisa. Entretanto, "outro veio 
colonizador pelas cabeçeiras dos Rios Fanado, Setúbal e pelo Alto dos Bois" (RIBEIRO, 1994), em direção ao vale do rio Mucuri, sendo este mais insalubre e perigoso. Digne-se que nas regiões espírito-santense e de Manhuaçu, direcionava-se as explorações para o rio Doce e Mucuri.

Muitos foram os colonos a se aventurar na abertura de novas terras, estradas e descobertas de jazidas, mas poucos fixavam moradia, segundo RIBEIRO (1994, p. 18). Antônio José Coelho, teria sido o primeiro morador fixo em Teófilo Otoni, em 1850, de acordo com o historiador Godofredo Ferreira para montar a Fazenda Mestre de Campo, levando consigo seus familiares, escravos e índios. Diferentemente do latifúndio da cana-deaçúcar e café, no vale do rio Mucuri, o sistema agrário se deu através das fazendas, extração de madeira e sistema de subsistência (1994, p. 21).

O rio Cricaré, hoje S. Matheus, tem suas nascentes no município de Theóphilo Ottoni, as quais, mais tarde, foram exploradas pelo Mestre de Campo João da Silva Guimarães, cuidando da extração de ouro e pedras preciosas (PORTO, 1929, p. 7).

O povoamento, partindo da idéia de como a economia forçava a integração, destacou três regiões: Alto Jequitinhonha, médio Jequitinhonha e o Mucuri, tendo uma intimidade, quando relacionadas com a direção do avanço da colonização. A exploração mineral se deu com maior intensidade na cidade de Ouro Preto, e, durante 100 anos avançou em direção a Diamantina, sendo o centro econômico e, depois ao Alto Jequitinhonha pela exploração do ouro e diamante, permanecendo o Mucuri ainda não explorado até fins do sec. XVIII e início do sec. XIX.

"Entretanto, aos primeiros sinais de esgotamento das minas, os atos proibitivos perderam força e, mesmo antes de serem abolidos, o governo colonial tornou a se interessar pelo território coberto pela Mata Atlântica" (ESPINDOLA, 2005, p. 31). A população foi se refluindo, e a dispersão populacional buscando outras atividades. Entretanto, permanecendo elas nos locais das minas, ficariam muito prejudicadas e impedidas, iniciando-se então a colonização das demais regiões.

O sistema agrário, no início do povoamento do Alto Jequitinhonha, era de subsistência nas grotas, equivalente a $15 \%$ da área segundo RIBEIRO (1994), e após os 100 (cem) anos de exploração, a produtividade já dava sinais de estagnação, e, não existia abundância, criava-se todo o processo de insatisfação do agrário, buscando-se outras possibilidades. Daí aparece três fluxos de povoamento: o primeiro do Cerro para o Rio Doce, o segundo de Minas Novas, no do chapadão do alagadiço para o Mucuri, e, por último, de Araçuaí para o baixo Jequitinhonha.

A ordem cronológica desta arrancada, rumo ao povoamento destes vales, se deu na ordem seguinte, primeiro para o rio Doce, depois para o baixo Jequitinhonha e o terceiro para o Mucuri, todos intencionados na descoberta ou "por caminhos onde mais tarde se encontraram as pedras verdes, numa serra situada na confluência das bacias dos rios Doce, Mucuri e São Mateus (Cricaré)" (ESPINDOLA, 2005. p. 35). “...assinalando claramente o interesse pelas esmeraldas. Mais do que isso, refere-se às minas da Serra das Esmeraldas (ESPINDOLA, 2005, p. 37). 
Teixeira Guedes, cujo destino era explorar amethistas nas circunvizinhanças do córrego do Ouro, deixando Minas Novas, ponto inicial de sua excursão, veio ter ao Valle do Mucury, onde, depois de ter denominado de pedra d'Agua a um dos ribeirões encontrados e de fazer explorações nos terrenos marginaes ao Rio Mucury, subiu ao cume de uma grande pedra (Pedra d'Agua) e observou que as margens do dito rio eram ocupadas por capoeiras.

Por informações do índio que the servia de guia, aquelles sítios foram "os de sua antiga residência e de mais outras nações Maconim - Capoxes - expulsos pela fereza do gentio Botocudo; sendo que já ali habitou um João da Silva com escravos em outros tempos".

Mais tarde, ficou com a denominação de Mestre de Campo, uma grande fazenda aberta no valle do Mucury, onde hoje está estabelecida a Colônia Francisco Sá. (PORTO, 1929, p. 12 e 13).

Ainda segundo PORTO (1929, p. 13 e 14) tinha outra frente de colonização do litoral rio acima até a cachoeira de Santa Clara. Partia da Vila de São José de Porto Alegre (Barra do Rio Mucuri/BA) indo a Nanuque, ficando impedidos de prosseguir, em razão da febre amarela, da inospitalidade das matas muito fechadas e da violência das guerras que travavam com os índios, os Botocudos “...índios antropófagos, terror dos brancos e dos outros índios. Estes nunca existiram além da imagem construída no final do século 18 e princípio do 19" (ESPINDOLA, 2005, p. 27).

\footnotetext{
...acabamos de transcrever de trechos do relatório de João da Silva Santos, vemos que ele subiu o Mucury até as cachoeiras e foi deste ponto, a seis léguas de distância que encontrou, a aldeia do bárbaro gentio, de acordo com as informações colhidas de pessoas de sua expedição.

D'ahi não passou João da Silva Santos porque não faz menção dos principais afluentes do rio Mucury, os quais, como se sabe, estão bem para cima, a principiar pelos rios Pampam, Todos os Santos, etc. (PORTO, 1929, p. 16).
}

Os objetivos dos colonos dentro das matas, inicialmente, eram três, sendo: as lavras, pois acreditava-se que existia uma riqueza absoluta e inexplorada, isso estimulava a aventura; também as lavouras, estas no Alto do Jequitinhonha, caminhando para o esgotamento em uma terra super partilhada dentro da mesma família, marcada pela grande prosperidade e na necessidade de apertar a população para a busca de novas terras e, por último, pelo fim da preação, costume que existia até o final do século XIX, onde se buscava o índio para civilizá-lo e o colocava para trabalhar.

Porém, havia um projeto colonizador de Ottoni, que não era um processo diverso como dos outros colonizadores, era um processo sofisticado, mas que teve o mesmo relacionamento com a mata (do interior para o litoral) de quem povoou o Mucuri. O interesse de Theóphilo Benedicto Ottoni, baseado no comércio, acreditava alcançar uma potencialidade de 100 mil consumidores a partir da cidade de Minas Novas. Acreditava também que com o monopólio da Companhia Vale do Mucuri, obteria grande sucesso. 
Confiante no relatório fantasioso do engenheiro Pedro Victor Renaut, que o rio Mucuri era completamente navegável e que o mesmo daria suporte para a exportação da farta produção local e importação, acreditavase que, assim, fosse possível evitar uma viagem comprida do Rio de Janeiro/RJ até Minas Novas/MG. Ainda sustentava-se a idéia de que com o escoamento da produção e que somente com o comércio do sal, haveria a sustentabilidade da Empresa. Não deu certo, pois vários fatores não contribuíram para sua efetivação, o comércio não atingiu patamares especulados e o rio Mucuri não era totalmente navegável.

"A comunicação com a Bahia era feita pelo rio das Velhas e o São Francisco, tanto por caminho terrestre como pela navegação, ou cortando os vales dos rios Jequitinhonha e Pardo pela borda oeste da floresta" (ESPINDOLA, 2005. p. 29). O período de estagnação, assim chamado, após a saída de Ottoni, na verdade não foi o período assim transicionado, pois o desinteresse do governo geral pelo projeto, as duas secas no agreste baiano (1890 e 1930) e a baixa produtividade nas grotas do Jequitinhonha, levaram então as famílias para o vale do Mucuri (Filadelfia).

Em 1728, o Vice-Rei Vasco Fernandes, depois de receber notícia que ao norte do rio Doce descobriram-se algumas esmeraldas de muita dureza e de cor muito clara, ao invés de proibir, mandou em diligência Braz Esteves Leme, concedendo-lhe o título de "superintendente de todas as minas que ele descobrir, ou por sua ordem descobrirem nos distritos e cabeceiras do rio São Mateus". (ESPINDOLA, 2005. p. 30).

Já no final do século dezenove começaram a chegar à mata os baianos, em quantidade crescente. A bem da verdade, nem todos eram baianos; boa parte era mineiro mesmo, do alto Norte: Espinosa, Taiobeiras, Salinas. A primeira grande leva deles desceu do rio Pardo, fugindo da famosa "Seca do noventinha", de 1890. Vinham em grandes grupos, e faziam sua primeira parada no Comercinho do Bruno. Alí escolhiam caminhos: das gerais, pela Itira, da Mata, pela Fortaleza ou São Roque, que era como se chamavam Pedra Azul e Itaobim. Tomando o caminho da Itira, poderiam abrir posses nos capões do alto Jequitinhonha. Como a terra lá era mais fraca, muitos seguiam em frente, passavam pelo Araçuaí, deixavam para trás o vale do Jequitinhonha, chegavam às cabeceiras do Mucuri e posse. Pouco depois de chegados ali encontraram algo muito pior que a seca: a varíola, que grassou por uns três anos em todo alto Mucuri, liquidando moradores às centenas. (RIBEIRO, 1994. p. 19).

Os vales dos rios Doce, Mucuri e Jequitinhonha, ilhas progressistas "na transição da economia de base da mineração para a agropecuária, configurou-se a diferenciação regional que caracterizou Minas Gerais no século 19" (ESPINDOLA, 2005, p. 49), pois Minas era um adensamento de várias regiões autônomas que sobreviveram e desenvolveram-se independentemente. Os mineiros sempre tentaram tratar Minas como uma unidade forte e sempre com altos interesses de negócios para o restante do país, construída meio na marra e chamada de mineiridade, visava converter-se numa unidade econômica e política. 
A colonização do vale do rio Todos os Santos, segundo PORTO (1929, pp. 29, 30 e 31) relata o empenho do Governo da Província de Minas, em traçar uma via em apoio à comunicação entre a região decadente de Minas Novas e o porto. Para construírem uma estrada, em 22 de janeiro do ano de 1836, partiu de Ouro Preto, o engenheiro Pedro Victor Renauld, sendo esta viagem de grande importância para o estabelecimento da Companhia do Comércio e Navegação do Rio Mucuri, em 1847, por Ottoni, o que seria a salvação da região em local denominado Philadelphia (Teófilo Otoni).

\begin{abstract}
Em 1811 o coronel Bento Lourenço Vaz de Abreu e Lima fez exploração de uma estrada pelo Valle do Mucury até S. José do Porto Alegre, pretendendo ligar o norte de Minas ao litoral. "Essa expedição, como muito bem disse o Dr. Miguel de Teive e Argollo, em opúsculo "Viação Férrea do Norte de Minas" attrahiu a attenção do ilustre ministro do D. João VI, o Conde de Barca, o qual mandou abrir uma estrada que de Minas Novas se dirigisse ao Oceano. (PORTO, 1929, p. 17).
\end{abstract}

Construída por Ottoni, a estrada de rodagem de Santa Clara a Teófilo Otoni, foi a primeira rodovia do Brasil Império que, segundo CERQUEIRA NETO (2001, pp. 30 e 31), é a primeira grande obra na Região do Vale do Mucuri. Em seguida, outra grande e importante estrada é iniciada. No ano de 1881, as obras da Estrada de Ferro Bahia-Minas (EFBM) tinham o objetivo de ligar o interior de Minas a Bahia, indo até o litoral, mais precisamente de Araçuaí/MG a Caravelas - Ponta de Areia/BA, com 578 km de extensão.

\begin{abstract}
...a estrada de Ferro Bahia e Minas, que ligava Caravelas, Teófilo Otoni e Araçuaí - Jequitinhonha e Mucuri, e os dois ao mar e ao mundo - simbolizou essa união de origem, que depois foi esquecida. Embora os dois Jequitinhonhas sejam hoje diferentes e separados, entre si e do Mucuri, a apartação não resiste a um exame da história de duas ou três gerações para trás. (RIBEIRO, 1994, p. 19).
\end{abstract}

Em substituição a esta importante ferrovia, foi construída a estrada de rodagem "Estrada do Boi". Até 1950, o Mucuri era diversificado e autônomo, mas logo o declínio econômico aparece. Então, a relação do homem com o vale do Mucuri, que veio de uma formação extrativista permanece, porém, com pequenos sintomas de desenvolvimento. E, a partir de 1955, com governo Kubistchek, onde há centralização da atenção econômica e política, com autonomia local pequena, sucumbiu-se ao eixo nervoso administrativo e político-econômico.

As condições de renda e poder econômico que haviam comportado com altíssima produtividade agrícola e pecuária no primeiro ciclo, após o desmatamento e a sequência de replantio reduziram-se. O mesmo se deu com as reservas ambientais, pois numa baixada que fica entre o rio Santo Antônio e o rio Todos os Santos, alvo de aglomeração do povoado, sendo a criança que fez Teófilo Otoni, foi aberta densa mata, habitada por indígenas selvagens de tribos diferentes, sendo Botocudos, Malali, Maxacali que nela circulavam. 
Ottoni contratou um cidadão insolvente na corte, o senhor José Pereira da Silva, negociante em Grão Mogol. Tinha uma boa escravatura e com ela fez a grande derrubada nesta confluência dos rios acima citados, arrasando também com queimada toda a área que se diz superior a 60 alqueires, incluindo gigantescos Jequitibás, Perobas e os Jacarandás milenares, superando muitas dificuldades, inclusive para que os índios não se aproximassem pela densa mata e pudessem ver e cobiçar as bugigangas do seu comércio.

\footnotetext{
Pela ação da própria natureza tudo melhora, mas não é suficiente para 0 bem geral do todos. $O$ homem continua agindo e maltratando a natureza com seus atos predatórios, procedendo como um elemento perturbador, praticamente um vivente irracional.

$\mathrm{Na}$ cidade de Teófilo Otoni temos as provas dos mais duros golpes dados contra a natureza.

Uma simples pergunta abre o caminho para um entendimento triste e acabrunhador:

Onde está o rio Todos os Santos, volumoso e agressivo, com vinte metros de largura e a profundidade regular de um metro $e$ meio, com seus barqueiros que chegavam e partiam no transporte de mercadorias, a cantar radiantes, na superfície das águas? (LORENTZ, 1990, p. 34 e 35)
}

Uma baixada que fica entre o Rio Santo Antônio e o Rio Todos os Santos foi alvo de aglomeração de povoado, portanto, o povoado de Philadelphia das Minas Gerais, que é a criança que se fez Teófilo Otoni foi aberta desta mata densa de que já se escreveu anteriormente, habitada por indígenas selvagens de tribos diferentes que ali circulavam. Ottoni contratou um cidadão insolvente na corte, o Sr. José Pereira da Silva, negociante em Grão Mogol. Tinha uma boa escravatura e com ela fez a grande derrubada nesta confluência dos rios.

Esta ocupação da mata virgem, não diferente das demais, veio arrasando também com queimadas toda esta área que se diz superior a 60 alqueires, incluindo gigantescos Jequitibás, Perobas e os Jacarandás milenares, superando muitas dificuldades, inclusive para que os índios não se aproximassem pela densa mata e pudessem ver e cobiçar as bugigangas do seu comércio. Sempre abrindo e derrubando a mata margeando o rio e afora, para poder servir de ponto de referencia e de negócio.

"A marcação da Rua Direita, feita pelo Engenheiro Alemão então pode ser traçada e concluída e montados os seus barracões para a instalação da Empresa Mucuri, a que se destinava todo o empreendimento" (LORENTZ, 1992.). Assim, os rios traduzem a grandeza de uma região. Se são volumosos e se conservam o volume, significam que as terras de sua bacia estão com a vegetação intacta, recolhendo todas as águas das chuvas que se infiltram e alimentam. (LORENTZ, 1992, p. 54). Daí sugerir que o homem agiu alucinadamente ao destruir a floresta para povoar. 


\section{A Devastação Ambiental e Seus Reflexos Regionais}

Neste contexto, de colonização de área para implantação de processos econômicos e instalação de cidades, como no caso de Teófilo Otoni, tornase imprescindível tratar e discutir a questão relacionada à devastação ambiental e seus reflexos regionais.

A vegetação natural é bastante rica e variada: grandes florestas equatoriais, florestas tropicais, cerrados e campos. É bem verdade que boa parte dessa vegetação já foi devastada pela ação antrópica sob forma de desmatamento para a formação das pastagens ou plantio nas fazendas e ainda a exploração de minerais ou pedras preciosas, para a construção da cidade ou abertura das rodovias.

A exemplo da região em destaque, a devastação das florestas foi responsável tanto para mudar o aspecto paisagístico como também a economia que girava em torno das serrarias e, na maioria, aglomeravam-se em Nanuque, cidade que foi fundada em 1911 por um madeireiro experiente vindo do Espírito Santo. Instalou aí sua serraria, em Caixa D' Água (Nanuque), sendo inaugurada em 1912 com o nome de Serraria Industrial do Mucuri. O serrador João Américo Machado, com seu empreendimento deu o pontapé inicial para o crescimento da cidade.

O desenvolvimento direcionou-se também para a economia, e, juntamente com ela a devastação das matas da região do Vale do Rio Mucuri. Ocorreu a ampliação de muitas outras serrarias que se instalaram posteriormente, pois nesta região havia uma mata só, ofertando as mais diversas e valiosas espécies de madeiras para o ofício. Portanto, verifica-se que quando se passa pela região, nas estradas, observa-se que apenas algumas manchas de mata ainda resistem, o restante é um campo aberto de colonião ou brachiaria.

Em verdade, o homem agiu alucinadamente, Destruiu a floresta e com ela os animais de caça, destruiu os rios e acabou com a pesca. Na volúpia de destruir, deformando a paisagem natural no centro da cidade e nas elevações que a circundam. Sedento de destruir, destruiu mesmo, sem necessidade, o monumento do fundador da cidade. (LORENTZ, 1992, p. 35).

A maneira com que as pessoas interessadas no assunto, tratam da conservação do patrimônio ecológico, diverge de um modo completamente diferente das demais discussões sobre estruturas diversas da sociedade, a exemplo de como a política chama de revolução nos dicionários, sendo "revolução armada, conflagração, transformação radical na estrutura econômica, política, social, cultural ou científica." Seria um movimento para tumultuar a estabilidade ou requerimento de direitos negados pelo Estado.

Entretanto, no caso ambiental, revolução seria o movimento de evolução dos métodos com os quais a proteção se manifesta na sociedade, ou ainda, a educação ambiental que chega aos países do primeiro mundo desde a década de 1970, mas também alcançou os países subequatoriais da mesma forma, apesar de apresentarem problemática diferente, em se tratando de casos específicos dessa região, mas a revolução que se trata nesse caso, atinge o mesmo espírito, o signo da preocupação ou da forma de desejar o bem comum na relação com os recursos. 


\begin{abstract}
Conservacionismo ou conservação dos recursos naturais é o nome que se dá a moderna preocupação em utilizar adequadamente os aspectos da natureza que o homem transforma ou consome. Conservar neste caso, não significa guardar, e sim utilizar racionalmente. A natureza deve ser consumida ou utilizada para atender às necessidades do presente, futuro, as novas gerações que ainda não nasceram, mas para as quais temos a obrigação de deixar um meio ambiente sadio. Foi somente a partir da degradação do meio ambiente pelo homem - e da extinção de inúmeras espécies animais e vegetais que surgiu essa preocupação conservacionista... (VESETINI. 1994, p. 247).
\end{abstract}

\title{
2.1. A Influência dos Recursos Hídricos
}

Os rios que fazem parte da Bacia do rio Mucuri, seus principais afluentes, e, em especial a micro bacia do rio Todos os Santos, situados no Leste de Minas, ora verso da capa do livro Zoneamento das Águas (MACIEL Jr. 2000), estão localizados em região tropical, subequatorial, e, segundo VESENTINI (1994), são normalmente caudalosos, numerosos e nunca secam ou congelam.

A intensidade e o volume de suas águas dependem basicamente das chuvas, ou seja, são rios de regime pluvial.

A beleza das águas nas nascentes proporciona uma paisagem, um espetáculo, objeto de admiração e não podemos nem pensar o que seria do ambiente sem a presença imponente das cachoeiras onde a natureza mostra sua força. "...a micro bacia, além de dar origem aos cursos d água, nos presenteia com inúmeras paisagens, pois, por serem geralmente montanhosas, apresentam o elemento água escoando em grande velocidade e com aspecto cristalino." (ALVES. 2000. p. 09)

Mas a interferência do homem tem quebrado o equilíbrio natural, o que poderá transferir para as gerações futuras uma situação de convivência indesejável no que se refere à disponibilidade e à qualidade das águas. Apesar de uma grande parcela de pessoas ignorarem a atual situação dos mananciais de água e a redução de sua produção, existe de fato, visto a olho nu, este fato de conversão dos volumosos e cristalinos recursos hídricos em, praticamente extintos ou convertidos em canais de esgoto.

A pressão sobre os recursos hídricos faz com que se desperte toda uma especial atenção sobre a região montanhosa onde começam os cursos d' água, a formação das nascentes. O desenvolvimento dessas regiões, com características de integração e sustentabilidade requer garantia da segurança da produção de água em quantidade e qualidade satisfatória, ao uso e a perenidade, com capacidade de atender a demanda atual e, garantir, segundo os fundamentos da legislação ambiental, recursos para as populações futuras.

"Uma propriedade com pouca ou nenhuma produção de água, certamente não poderá ensejar a execução de algum empreendimento" (CASTRO, 2001). A proposta imaginária é de partir da foz do rio para o interior, perceber que a paisagem rio acima é dinâmica, passar por 
afluentes menores, depois continuar esta mesma empreitada, mas ao sair dos rios principais e encontrar ribeirões e córregos, que bem menores e em regiões mais altas, pode-se dizer que aí se formam as bacias de cabeceiras onde encontram as nascentes.

"As micro bacias ou bacias de cabeceiras, são pequenas áreas de terras localizadas em regiões montanhosas, que formam as nascentes e drenam córregos e riachos." (ALVES, 2000. p. 09). As nascentes são os locais onde jorra água através da superfície do solo, e pode-se concluir que estas são provenientes de reservatórios subterrâneos, pois os olhos d água e os difusos brotam vindos do interior da terra. Mas, é necessário compreender a existência de vários fatores responsáveis pela origem destas nascentes: o ciclo hidrológico, estrutura dos solos e armazenamento.

\begin{abstract}
As micro bacias, ambiente responsável pela origem da água, elemento purificador, formam um verdadeiro jardim natural, que devido a sua escala, facilitam a percepção humana como unidade paisagística. Comparado ao Jardim do Éden, citado na Bíblia, onde o "Senhor Deus fez brotar da terra toda sorte de árvores de aspecto agradável e de frutos bons para comer... e de onde saía um rio para regar o jardim", o ambiente das micro bacias deve ser considerado como verdadeiro santuário ecológico". (ALVES, 2000, p. 9).
\end{abstract}

Em relação às sub-bacias hidrográficas, vale observar as regiões montanhosas, de topografias irregulares, e perceber algo comum entre elas. Segundo CASTRO (2001), importante verificar topos de morros, suas encostas e os vales que por pequeno que seja, não sendo áridos, há de encontrar alguma, senão várias nascentes provenientes de um aqüífero freático que viera de uma reserva da precipitação que caiu e se alojou, após percolar por seu solo poroso e independente do seu tamanho e seu volume sendo interligados como Bacia Hidrográfica.

"Bacia Hidrográfica refere-se à área do terreno que coleta e infiltra a água da chuva, que abastece os reservatórios subterrâneos de água, que darão origem as nascentes" (CASTRO, 2001. p. 22) e a bacia hidrográfica é formada por diversas bacias menores de seus afluentes que se denomina sub-bacias hidrográficas. Ainda sobre a ótica das divisões e subdivisões por divisor topográfico, nota-se que esta é a linha que limita a área de drenagem e corresponde ao topo das encostas, sendo que o divisor freático fica abaixo da superfície do solo e direciona a água percolada.

Quando a área de drenagem de uma bacia hidrográfica, que, conforme visto no parágrafo anterior como divisor topográfico, é maior, será também mais abundante sua capacidade de coletar a precipitação. Já a área superficial desta bacia, destacada pela área mais plana e baixa, de menor declividade, que pode geralmente localizar-se sobre o lençol freático e/ou lençol artesiano, denomina-se de "área de contribuição dinâmica." (CASTRO, 2001). 


\section{O Rio Todos os Santos}

Tratar especialmente do Rio Todos os Santos, nas áreas de suas nascentes é uma forma de transferir para este relato, uma oportunidade de poder visualizar o estado em que se encontra sua cabeceira. Para tanto, torna-se necessário obter relatos de pessoas que vivem nessas áreas, que estão, de certa forma, designados a conviverem com seus recursos, e em especial, estão lutando pela sua condição de defensores contra a degradação que impõe a ocupação antrópica.

Esta experiência colocada à disposição em dados sobre a quantidade, localização e até mesmo averiguação nas encostas, nos olhos d água, conota uma configuração empírica à parte deste capítulo. $O$ ambiente destacado envolve centenas de propriedades rurais nas quais dezenas delas foram visitadas e selecionadas a fazer parte dos relatos de parte deste trabalho, porém, o que se pretende com este entrelaçamento não é somente o relacionamento pessoal, mas também com as informações sobre as nascentes.

Tudo que envolve as matas de topo, as matas ciliares ou ripárias, as regiões de contribuição dinâmica, incluindo as nascentes difusas e olhos d água, e, por fim, os cursos d água são objetos de estudo de nascentes. Diante desta característica, prende a pesquisa ao estudo dos recursos hídricos e prorroga para mais distante a relação das pessoas com este meio ambiente, pois faz parte de um projeto para o futuro, o que poderia divergir dos objetivos gerais e específicos que contornam este estudo.

Pensar rios e córregos na atualidade é deparar com várias correntes que defendem todo tipo de intervenção, mas que na sua maioria, não conseguem atingir a idéia de torná-los semelhantes ao que eram no passado, caudalosos e límpidos, navegáveis e rentáveis como fonte de alimentos na atividade pesqueira. As atividades antrópicas impõem para satisfação de seus projetos, que são a canalização, retificação, desmatamento, assoreamento, emissão de efluentes entre outros meios impeditivos de retorno.

Estas condições impostas aos rios e córregos na área urbana, que condicionam sua degradação enquanto elemento da natureza, levam a perda da qualidade de vida das pessoas que dependem de suas águas. Característica diferente do que ocorre na área rural e região de cabeceiras. Uma delas motivada pelo número de pessoas que interferem nos processos, pois, na área urbana, pelo aumento da população no século passado e pela implantação de indústrias, os impactos são intensos.

Os processos de renaturalização e revitalização através da engenharia ambiental e outras profissões afins, são alento àqueles que acreditam num futuro saudável, na qualidade da água natural como condição de saúde e no resgate da função simbólica, lúdica e de lazer e entretenimento que os rios podem proporcionar, principalmente na área urbana, desprovida de outros centros de lazer, como é o caso das cidades da região desta micro bacia do vale do Rio Todos os Santos, maior e principal afluente do Rio Mucuri que dá nome ao vale. 
Já o estado em que se encontram as regiões de cabeceira dos principais afluentes do Rio Todos os Santos, subafluentes do Rio Mucuri leva a preocupação com os aspectos ambientais de desmatamento descontrolado, seja através de manejos inadequados ou como fonte de melhorar e especular o valor das propriedades rurais, queimadas, devastação que tem atingido regiões que abrangem as matas dos topos das montanhas, matas ciliares, o entorno das nascentes, proporcionando uma redução do volume d’água que depende destes fatores.

\subsection{Descrição de Alguns Afluentes}

Os dados descritos abaixo foram coletados em várias visitas in loco e não apresentam localização geográfica, mas o sentido em que se encontram. No município de Poté, propriedade do Sr. Sebastião Rodrigues dos Santos, têm preservados todos os topos dos morros e baixada, só usa madeira seca, pode ser vista a primeira nascente do Rio Todos os Santos, fica numa bacia formada pela vertente topográfica dos Rios São Mateus (Cricaré), Rio Valão e o Rio Todos os Santos.

Esta área cercada por montanhas tem eminentemente característica de arrecadadora de água para a formação do lençol freático, pois tem a forma côncava e a presença de um único corredor de saída para o curso do rio que aí nasce sob a forma de olhos d água, direcionam sua orientação rumo às propriedades que estão abaixo, prontas para receberem em sua sinuosidade e pequenas cachoeiras, o precioso e importante produto que dispõe sem nenhum ônus para aqueles que utilizam na lavoura e uso doméstico.

A área de contribuição dinâmica da nascente principal do Rio Todos os Santos, tem uma vegetação diversificada, não sofreu intervenção antrópica de forma contundente, onde orientações permanentes têm sido formuladas no sentido da continuidade da preservação nesta área, e, que já se fazia devido à importância para esta propriedade e as demais do recurso hídrico que aí se inicia. Tendo todo cuidado com o cercamento dos olhos d água com postes de eucalipto, arame e ajuda de voluntários, a Prefeitura de Poté, EMATER-MG e COPASA.

Ainda nesta propriedade, logo abaixo uns 100 (cem) metros do primeiro olho d água, nos fundos da casa do proprietário, o primeiro filete do rio já com uso doméstico. A força do Todos os Santos começa com alguns riscos semelhantes a uma cadeia de neurônios que vão se interligando para formar o curso d água. Num espaço pouco mais de 500 (quinhentos) percorridos, já se contempla nesta micro bacia por mais 5 (cinco) nascentes, vindas de outras propriedades, todas com as mesmas características, muita vegetação ainda conservada.

Destaque para o esgotamento de brejos nesta região já abaixo da nascente, rebaixando e alinhando com o retilineamento do curso do rio, com a finalidade de utilizar a área esgotada como pastagens, cuja atividade com o gado é a principal das propriedades. Ainda há pouco tempo atrás, havia cultivo de café, com aproximadamente um milhão e setecentos mil pés desta planta, que foi completamente arrancada e substituída por capim 
brachiaria. Tal manejo contribui para mudança nas características paisagísticas da região.

Desprovida de matas de cobertura dos topos dos morros, não existindo vegetação ciliar (ripária), que afetam significativamente o ecossistema a que pertence. Na comunidade denominada de Baixinha de Todos os Santos, tem o primeiro lugarejo comunitário do uso da água do Rio Todos os Santos, com aproximadamente 60 (sessenta) casas. O recurso hídrico é usado de formas diversas, o uso doméstico, lavoura, suinocultura e piscicultura. Rio abaixo, a represa de captação da cidade de Valão mostra o volume que tem esse rio.

O córrego Leme, alguns quilômetros abaixo, afluente do Rio Todos os Santos, encontra-se com o protagonista na propriedade pesque e pague de Valão, que tem 13 (treze) represas pequenas e (01) uma grande para exploração e criatório de peixes. A impressão que visivelmente se tem, é a de que dentro da cidade de Valão, o volume $d^{\prime}$ água é bem menor que antes de passar pelas represas. A presença de muitas cachoeiras durante o percurso do rio abaixo são constantes, quedas muito variadas e, rumo a Teófilo Otoni são vistas muitas outras nascentes.

$\mathrm{Na}$ baixada de Valão já nos encanta o tamanho do rio, pois um curso que já necessita de uma ponte, evidencia seu porte. Num trajeto sinuoso e longo, lento, às vezes, viaja-se muito até o local importante para a população urbana. Na Fazenda Boa Vista, encontra-se a represa da COPASA, a antiga em funcionamento e a nova sendo construída para poder sustentar no período seco, o abastecimento de água de Teófilo Otoni. O volume da vazão em questão é de 110 litros-segundo na seca e até 300 na safra.

Nesta Fazenda Boa Vista, o Rio Todos os Santos oferece aos olhos da população, vários exemplos de belíssimas paisagens naturais, exemplares de cachoeiras naturais, com remansos embaixo de pés de Ingá, sem contar que sua sinuosidade garante sua naturalidade. Nas vizinhanças da fazenda Boa Vista, em sentido às nascentes do Rio São José, têm relatos de grandes devastações de mata primária, na época em que passava por esta região a Estrada de Ferro Bahia Minas, com sua locomotiva Maria Fumaça.

O Rio São José, um afluente importante do Rio Todos os Santos tem suas nascentes nas vertentes da nascente do Rio São Mateus, embora dividindo com o município de Itambacuri, na propriedade do Sr. Eder Sampaio, onde corre o primeiro filete de água rumo a Teófilo Otoni, que irá se fortalecer com mais duas nascentes bem próximas. Cerca de 800 metros abaixo já se pode contemplar visualmente duas represas, uma de porte menor com cafezais de um lado e mata do outro, e a segunda com o espelho d'água maior rodeada de pastagens e pouca vegetação.

$\mathrm{Na}$ nascente do córrego Linha $\mathrm{H}$, um ponto de relevo de altitude expressiva, também nas divisas de município, sub afluente do Rio São José, ocorre fato que serve para ilustrar inúmeros ataques à preservação das nascentes desta região. Foi desmatada toda a propriedade, inclusive ao redor da nascente para formação de pasto para alimentação de gado. Exterminada a vegetação ao redor da nascente, descaracterizando a paisagem, certamente servirá de agravante para que esta nascente precocemente se extinga. 
O córrego Água Preta, que desaguará no córrego São Gotardo, apresenta um diferencial dos demais, pois a sua nascente é difusa, enquanto a maioria são olhos d' água, numa região de relevo declivoso, com muitas grotas. Nesta propriedade, a natureza ainda é preservada com matas de topo e vegetação ciliar ou ripária constante. Ainda rio abaixo, o córrego São Gotardo nasce numa pequena bacia formada por uma cadeia de morros, um olho d' água à direita, outro logo abaixo, numa pedra e vários noutra grota, formando este córrego também com nome de santo.

O córrego Suíça II, também chamado de Perigosos, subafluente do Rio São José, cuja nascente não diferencia das demais, desenha sua sinuosidade na propriedade de um assentamento de 21 (vinte e uma) famílias de agricultores, onde abastece um reservatório de 84 (oitenta e quatro) mil litros d água, todo abastecido por gravidade, sem necessidade de motor bomba, tanto para encher o reservatório quanto para a irrigação agrícola. Este reservatório construído sem muitos recursos de engenharia apresenta-se firme e sem vazamentos e serve aos seus propósitos.

Pouco abaixo já na área urbana na propriedade do Sr. Gilson de Castro Pires, uma nascente insiste em não secar, sua bacia de captação já sofrida por diversas queimadas, desprotegida de mata de topo e rodeada somente por pastagens. Neste ponto, o Rio São José, já composto pelo córrego Água Preta, o córrego São Gotardo, O Córrego Suíça II e vários outros pequenos cursos d'água, tem uma recente captação de água, um pouco mais moderna que a anteriormente construída na fazenda Boa Vista.

Apesar de mais curta a bacia deste afluente do Rio Todos os Santos, visivelmente nota-se um volume superior deste precioso líquido na estação da seca. O Rio São José tem o volume no seu leito maior que o Rio Todos os Santos. O fato do volume maior de água no Rio São José, em comparação ao Rio Todos os Santos, que tem uma extensão superior, deve-se ao fato de que existem mais subafluentes que deságuam no primeiro do que no segundo. Ainda o uso diversificado do recurso hídrico se dá com maior intensidade no Rio Todos os Santos.

Das inúmeras pequenas bacias visitadas para confecção desta parte do trabalho, as nascentes dos córregos Brejaúba e Capitólio não fogem às características das demais. Suas inúmeras nascentes demonstram como são importantes para as populações locais e que vão agigantar logo abaixo 0 rio protagonista deste empreendimento. Os $1^{\circ}$ e $2^{\circ}$ olhos $d^{\prime}$ água nascentes do córrego Brejaúba também vão desaguar no córrego Capitólio, destaque para um galho desse que tem 75 (setenta e cinco) milímetros cúbicos de volume na seca.

As demais nascentes até a 6ª , na propriedade do Sr. João Carlos Nunes Coelho, na vertente topográfica com o Rio São Mateus, e abaixo formam um total de 16 nascentes uma em cada pequena propriedade, abastecendo várias comunidades ribeirinhas cachoeiras abaixo. Percebese, pela topografia acidentada de toda região de cabeceira dos afluentes e subafluentes do Rio Todos os Santos, que são incontáveis os olhos d'água, mas que um levantamento minucioso o poderá fazer contá-las.

A intensidade e proximidade destes brotos d'água formam belíssimos cursos d'água, e estes subafluentes, os córregos Brejaúba e Capitólio desaguarão no córrego Lajinha, despejando esse conjunto no córrego 
Liberdade, região de agricultores de laranja, flores e plantas ornamentais. O córrego Poton recebe esses subafluentes, e se lançam no Rio Todos os Santos abaixo da zona urbana de Teófilo Otoni, que daí em diante continua recebendo vários outros, como córrego da Palha, Santaninha, Santana, São Paulino e vão completar o Rio Mucuri.

\section{CONSIDERAÇÕES FINAIS}

Percorrendo a história de Teófilo Otoni, e, sobretudo no que se refere ao processo de colonização do Vale do Mucuri, os dados obtidos demonstram, claramente, a importância dos recursos naturais e sua influência no processo de colonização, favorecendo, assim, um melhor entendimento acerca da relação dos indivíduos e o seu meio ambiente.

A partir do povoamento das cidades, puderam-se perceber os reflexos da exploração dos recursos minerais, da exploração agropecuária, mercantil e dos recursos hídricos e a conseqüente devastação ambiental.

Sobre bacias hidrográficas, ciclo hidrológico, aqüíferos sobre e subterrâneos e o levantamento de parte das nascentes nas cabeceiras do Rio Todos os Santos, por cerca de 374 (trezentos e setenta e quatro) quilômetros de estrada sem asfalto, fazem parte de uma integrada cadeia de fatores que parecem ter se incorporado e entrelaçado ao corpo dos pesquisadores e uns aos outros, fato é que, tamanha importância foi dado à pesquisa que se pretende dar continuidade em um novo projeto.

São vários os temas em destaque na mídia e meios legislativos e do executivo, mas os recursos hídricos têm um tratamento muito especial. As Secretarias de Meio Ambiente estaduais são chamadas a todo momento, o foco sobre queimadas, que influenciam sobremaneira na formação de cursos d'água, as convenções internacionais, a exemplo da Convenção para Proteção e Utilização dos Cursos de Água Transfronteiriços e dos Lagos Internacionais, de Helsinque 1992, preconizam o atendimento às necessidades atuais sem comprometer as futuras.

Fica então um pequeno roteiro de alguns dos afluentes e subafluentes que compõe a micro bacia do Rio Todos os Santos, principal afluente do Rio Mucuri, cuja região começa num cantinho do Estado de Minas Gerais, que pode ser seguido para dar seqüência ao estudo. Viajar no tempo junto aos colonizadores e chegar às cabeceiras do Rio nos dias atuais, serve para justificar nossa existência, e, mostrar que desse meio ambiente do Rio Todos os Santos, somos todos dependentes e talvez possamos contribuir para seu status de recurso hídrico indispensável.

\section{REFERÊNCIAS}

ALVES, Schirley Cavalcante. A água como elemento fundamental da paisagem em microbacias. Informe Agropecuário. - v.21, n.207, p. 9-14, nov./dez.2000. 
CASTRO, Paulo Sant'Anna, LOPES, José Demerval Saraiva. Recuperação e Conservação de Nascentes. Viçosa: CPT, 2001. 84 p.

DIAS, Herly Carlos Teixeira, PRUSKI, Fernando Falco. Revitalização de Rios: Área Rural. Ação Ambiental, Divisão Gráfica Universitária. UFV Universidade Federal de Viçosa, Ano VI, n. 24, p. 8-10, março/abril 2003.

DOMINGUES, Antônio Felix. Entrevista. Revitalização de Rios: Área Rural. Ação Ambiental, Divisão Gráfica Universitária. UFV - Universidade Federal de Viçosa, Ano VI, n. 24, p. 05-07, março/abril. 2003.

INFORME AGROPECUÁRIO. Manejo de Microbacias. Belo Horizonte: v. 21, n. 207, nov./dez. 2000.

INFORME AGROPECUÁRIO. Agropecuária e ambiente. Belo Horizonte: v. 21, n. 202, jan./fef. 2000.

ESPÍNDOLA, Haruf Salmen. "Sertão do Rio Doce". Bauru, SP: EDUSC, 2005. $488 \mathrm{p}$.

LANFREDI, Geraldo Ferreira. Política Ambiental, Busca de Efetividade de seus instrumentos. São Paulo: Revista dos Tribunais, 2002. 300 p.

LIMA, Walter de Paula. As matas Ciliares, Ação Ambiental, Divisão Gráfica Universitária. UFV - Universidade Federal de Viçosa, Ano VI, n. 24, p. 2022, mar./abr. 2003.

LORENTZ, Leônidas. "A batalha ecológica na cidade de Teófilo Otoni". Rio de Janeiro: 1990, $64 \mathrm{p}$.

LORENTZ, Leônidas. "A pobreza sofredora na cidade de Teófilo Otoni e temas ecológicos". Rio de Janeiro: 1992, 62 p.

MACIEL Jr., Paulo. Zoneamento das águas. 1 ed. Belo Horizonte: 2000. $112 \mathrm{p}$.

MACHADO, Paulo Afonso Leme. Direito Ambiental Brasileiro. 10 ed. São Paulo: Malheiros. 2002. 1038 p.

PORTO, Reinaldo Ottoni, "Notas Históricas". Município de Theóphilo Ottoni, Theóphilo Ottoni: Typographia S. Francisco, 1929. 38 p.

RIBEIRO, Eduardo Magalhães. "Lembranças da Terra - Histórias do Mucuri e Jequitinhonha". Contagem: CEDEFES, 1994, 235 p.

VESENTINI, José willian. Sociedade e espaço: Geografia Geral e do Brasil. 24 ed. São Paulo: Ática, 1994. 263 p.

WEIL, Simone. "O Enraizamento". Trad. Maria Leonor Loureiro. Bauru: EDUSC, 2001. $274 \mathrm{p}$. 